\title{
Proyectos literarios interdisciplinares con impacto social
}

\author{
Judith Schnettler; Martina Kienberger; Patricia Cifre Wibrow; \\ Belén Santana López
}

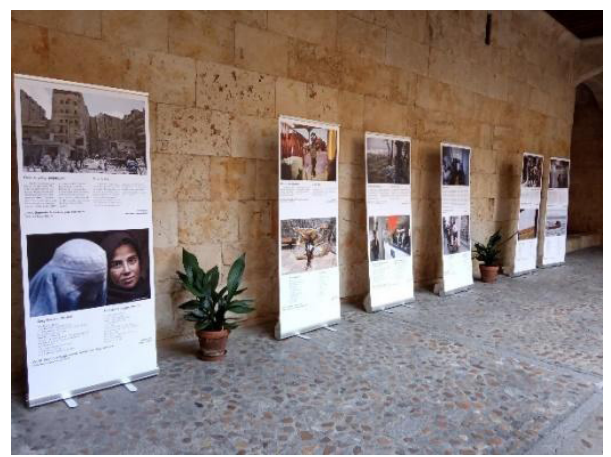

- A INICIATIVA CONSISTE en la realización de proyectos que trabajan temas de relevancia social, como la migración y la memoria histórica, con el fin de motivar al estudiante $\checkmark$ fomentando un aprendizaje interdisciplinar y dando visibilidad a su trabajo fuera de las aulas.

Se plantean diferentes objetivos:

- Integrar a los estudiantes en los procesos de selección de contenidos.

- Profundizar en las técnicas de interpretación y traducción literaria.

- Trabajar con diferentes medios (literatura, fotografía...).

- Estrechar los vínculos entre las Facultades de Filología y Traducción y Documentación.

- Aumentar el impacto de los estudios literarios abriéndolos a la ciudadanía.

- Contribuir a la educación en valores cívicos, tanto entre los alumnos como en la ciudadanía.

En este proyecto participan diferentes grupos de estudiantes de las Facultades de Filología y Traducción y Documentación que realizan el curso «Lírica alemana» o «Cultura y 
medios». También se cuenta con la implicación de varios docentes de estas facultades que imparten los cursos citados.

Se toma como referencia un proyecto previo realizado durante el curso 2017-2018 centrado en la memoria histórica de los países germanoparlantes. En el curso 2018-2019 se planificó un proyecto a mayor escala en el que el resultado de las actividades se convirtió en una exposición para así aumentar su impacto y visibilidad.

Concretamente, el proyecto desarrollado en el curso 20182019 consistió en la traducción al español de diez poemas, nueve pasajes narrativos y uno dramático, relacionados con los temas trabajados y que habían sido previamente seleccionados por las profesoras implicadas en el proyecto.

Finalmente, fueron seleccionados catorce textos para la exposición titulada Fuimos. Vamos. Iremos.

Los estudiantes escogieron las fotografías más adecuadas para cada texto de una colección elaborada por el fotógrafo salmantino Alberto Prieto para tal fin.

Los resultados del proyecto se presentaron en la citada exposición, que tuvo lugar del 19 al 30 de noviembre de 2018 en la Facultad de Filología de Salamanca. En diciembre del mismo año, la exposición se mostró en la biblioteca pública La Casa de las Conchas y a lo largo de 2019 en otros lugares de la geografía española (Santiago de Compostela, Valencia, Vitoria).

El carácter innovador de esta propuesta reside por un lado en el enfoque interdisciplinar debido a la colaboración entre las facultades implicadas, que favoreció el intercambio de metodologías y puntos de vista y, por otro lado, en que este modelo de aprendizaje favorece la implicación y motivación del estudiante.

En la asignatura Cultura y medios, el trabajo escrito en relación con el proyecto formó parte de la evaluación global, obteniendo resultados muy satisfactorios.

En el caso de la Traducción, el trabajo formó parte de la evaluación continua de la asignatura Prácticas de Traducción (alemán). Las alumnas destacaron el factor motivacional al tratarse de un encargo semiprofesional en circunstancias reales.

En la asignatura de Literatura alemana lírica, las traducciones formaron parte de la evaluación (10\% de la nota).

El gran interés público suscitado por la exposición demuestra que el proyecto logró un fuerte impacto fuera de las aulas.

Gracias a la red del DAAD (Servicio Alemán de Intercambio Académico) en España, la iniciativa se dio a conocer en diferentes ciudades universitarias del país.

Para la divulgación de la práctica se han utilizado los medios locales y las redes sociales. Además, el proyecto del curso 2018-2019 se presentó en un encuentro de lectores del DAAD en España. También se ha publicado un artículo sobre el proyecto del curso 2017-2018. 